NBER WORKING PAPER SERIES

\title{
CRIME AND THE TIMING OF WORK
}

Daniel S. Hamermesh

Working Paper 6613

http://www.nber.org/papers/w6613

\section{NATIONAL BUREAU OF ECONOMIC RESEARCH \\ 1050 Massachusetts Avenue \\ Cambridge, MA 02138 \\ June 1998}

I thank Philip Cook, Edward Glaeser, Steven Levitt, Daniel Nagin, and participants in seminars at several universities for helpful comments, Adam Anderson and Cyntiah Zoghi for helpful research assistance, and the National Science Foundation for support under grant SBR-9422429. Any opinions expressed are those of the author and not those of the National Bureau of Economic Research.

(C) 1998 by Daniel M. Hamermesh. All rights reserved. Short sections of text, not to exceed two paragraphs, may be quoted without explicit permission provided that full credit, including $\odot$ notice, is given to the source. 
Crime and the Timing of Work

Daniel S. Hamermesh

NBER Working Paper No. 6613

JEL Nos. J22, K42

June 1998

\section{ABSTRACT}

Two striking facts describe work timing in the United States: a lower propensity to work evenings and nights in large metropolitan areas, and a secular decline in such work since 1973. One explanation is higher and possibly increasing crime in large areas. I link Current Population Survey data on work timing to FBI crime reports. Neither fact is explained by changes in nor inter-area differences in crime rates, but higher homicide rates do reduce such work. This reduction implicitly costs the economy between $\$ 4$ and $\$ 10$ billion. This negative externality illustrates a larger class of previously unmeasured costs of social pathologies.

Daniel S. Hamermesh

Department of Economics

Univeristy of Texas

Austin, TX 78712-1173

and NBER

hamermesh@eco.utexas.edu 


\section{INTRODUCTION -- TWO TANTALIZING FACTS}

Elsewhere (Hamermesh [6, Chapter 3]) I have demonstrated that in the United States in 1991 workers in larger MSAs were less likely than workers elsewhere to be on the job in the evenings and at nights. The interesting question about this fact is what causes it -- what is there in the nature of large metropolitan areas that causes work to be bunched more during daylight hours? Crime, and even more the fear of crime, suggests itself as one possibility, since we know (e.g., from Glaeser et al.[4]) that crime is more prevalent in large cities. I consider here whether this explanation is correct and, more generally, how patterns of crime affect the timing of work. We can use the results to draw inferences about the existence and magnitude of some previously unexamined indirect economic costs of crime. This discussion points to a larger class of issues regarding the impact of social pathologies -- the welfare costs that they may generate because they shift work arrangements away from a firstbest allocation of workers across space and over time.

Studying the relationship of crime to work timing could also help resolve another intriguing puzzle. In Hamermesh [5] I show that between 1973 and 1991 there was a very sharp trend away from work in the evenings and at nights in the United States. Evening/nights are when the fear of crime is most likely to have had an effect. To what extent have the trends in work timing been produced by changes in patterns of crime?

Section II of this study presents models of the determination of the timing of work as it relates to crime. In Section III I describe the data that provide the central basis for the empirical work and also document the additional data used to analyze the nexus between work time and crime. In Section IV I examine the robustness of the relationship between MSA size and work timing and 
present an empirical analysis of the relation of crime to work timing. Section V uses the results of Section IV to infer the external costs of crime that spill over onto the labor market.

\section{MODELS OF WORK TIMING AND CRIME}

The worker's choice of timing has been presented completely by Winston [15]. Let a particular time of day be denoted by $\mathrm{t}(\mathrm{t}=1, \ldots, 24)$. Then the worker/consumer maximizes:

$$
\mathrm{V}_{\mathrm{i}}=\underset{\mathrm{t}}{\Sigma} \mathrm{U}_{\mathrm{it}}\left(\left[1-\mathrm{L}_{\mathrm{t}}\right], \mathrm{C}_{\mathrm{t}}\right),
$$

subject to $\underset{\mathrm{t}}{\sum}\left[\mathrm{w}_{\mathrm{i}} \mathrm{L}_{\mathrm{t}}-\mathrm{C}_{\mathrm{t}}\right]=0$,

where $\mathrm{L}$ is an indicator equaling 1 if person $\mathrm{i}$ works at time $\mathrm{t}, 0$ if he or she does not; $\mathrm{w}$ is the wage rate that person can obtain by working at time $\mathrm{t}$, and $\mathrm{C}$ is the amount consumed at time $\mathrm{t}$. Consumption and leisure are assumed to be separable in (1). Since the t denote small discrete intervals (hours), I assume that the person does not consume while at work, and I ignore discounting. We can view employers as being differentially able to generate profits by producing at various times of the day. Firm j's profit function is thus:

$$
\Pi_{j}=\Pi_{j}\left(a_{j 1} N_{1}, \ldots, a_{j 24} N_{24}\right),
$$

where $\mathrm{N}_{\mathrm{t}}$ is the number of workers employed at time $\mathrm{t}$, and $\mathrm{a}_{\mathrm{t}}$ is the contribution of a worker at time $\mathrm{t}$ to profits. Along with differences in the $\Pi_{\mathrm{j}}$, variations in the patterns of the $\mathrm{a}_{\mathrm{j} t}$ across firms will generate heterogeneity in firms' offers of work at different times.

The equilibrium allocation of work time is characterized by the assignment of workers to firms, as is standard in models of implicit markets (Rosen [10]). Workers whose reservation wage at times $t$ is lowest will be found working at those times in firms where the worker's productivity at $\mathrm{t}$ is highest, other things equal. Depending on the distributions of reservation wages across individuals and over all times $t$ during the day, and on the distributions of the $a_{j}$, the market will 
generate a pattern of equilibrium wage differentials $\theta_{\mathrm{t}}$. Each worker will face a vector of wages $\mathrm{w}_{\mathrm{it}}$ $=\mathrm{w}_{\mathrm{i}}\left[1+\theta_{\mathrm{t}}\right]$, where $\mathrm{w}_{\mathrm{i}}$ is the worker's wage rate at an arbitrarily chosen $\mathrm{t}$ at which $\theta_{\mathrm{t}}=0$. Presumably there are some t' that are viewed as undesirable (as disamenities) by relatively more workers than would be required to fill employers' labor demands at those $t^{\prime}$ if $\theta_{t^{\prime}}$ were zero. At those times $\theta_{t^{\prime}}>$ 0. Moreover, workers with lower full earnings will be more likely to be at work at those times than will otherwise identical workers: Assuming no correlation of tastes and full earnings, we will observe an income effect on the demand for the amenity, work at desirable times (daytime).

To account for the effects of crime, or fear of crime, on this allocation, modify workers' utility functions in this model as:

$$
\mathrm{V}_{\mathrm{i}}=\sum_{\mathrm{t}} \mathrm{U}_{\mathrm{it}}\left(\phi_{\mathrm{it}}\left[1-\mathrm{L}_{\mathrm{t}}\right], \mathrm{C}_{\mathrm{t}}\right)
$$

where $\phi_{\mathrm{it}}$ is a measure that differs among individuals and over $\mathrm{t}$ and indicates the extent to which individual i's value of leisure is increased by the amount (fear) of crime at time t. ${ }^{1}$ Introducing the $\phi_{\mathrm{it}}$ alters the equilibrium matching of workers and firms. To the extent that workers have similar patterns of the $\phi_{\mathrm{i}}$, employers seeking workers at those times when $\phi_{\mathrm{t}}$ is greatest will now have to offer a higher premium $\theta_{\mathfrak{v}}$, while the wage premia at those times when the $\phi_{\mathrm{t}}$ are low will be smaller. On the quantity side, less work will be performed at those times of the day when the $\phi_{\mathrm{t}}$ are high, and more will be accomplished at those times when they are small. Heterogeneity among workers in their $\phi_{\mathrm{it}}$ will alter the worker-firm match by time of day from what it was when we assumed $\phi_{\mathrm{it}} \equiv 0$. The work patterns of those workers $i$ who see the greatest dispersion over $t$ in their $\phi_{\mathrm{it}}$ will change most when crime is added to this model of labor supply/consumption.

Taken together the model predicts that where crime, or the fear of crime, is more widespread the pattern of work will, other things equal, be tilted away from those times when the danger is 
greatest. This deflection will be especially great for those workers whose potential losses as crime victims are large. By relating information on workers' choices of timing to city-specific measures of crime, we can infer whether city-size effects on work timing result from inter-area differences in crime rates.

\section{DATA AND DESCRIPTIVE STATISTICS}

Data on the timing of work are very rare in the United States and elsewhere. Fortunately, as part of the Multiple Jobholding Supplement to the May Current Population Surveys (CPS) in 197378, and again in 1985 and 1991, Bureau of Labor Statistics enumerators asked respondents when they usually started and ended work on their main jobs. ${ }^{2}$ The questions in the CPS are phrased as, "Last week at what time of day did ... begin [end] work on this job most days?" Given this phrasing, the responses presumably indicate when the person arrived at and left the workplace. Using the answers to these questions, we can construct measures of $\mathrm{L}_{\mathrm{t}}$ for each worker in the sample. The empirical analysis in this study is based on data from the surveys of 1973, 1978, 1985 and 1991.

The CPS also contains a wide variety of demographic information on the respondents. Thus in attempting to identify the effects of crime on the timing of work I also adjust for differences in: Years of schooling attained; labor-market experience (and its square), measured as age - years of schooling - 6; the respondent's race (African-American or other) and whether or not he or she is Hispanic; whether or not the person is married; and whether the person is located in the Northeast or Midwest. These demographic variables are included in all the linear regressions or probit analyses that examine the impact of crime on work timing; but because they are merely controls that are of little interest per se, I neither present nor discuss their effects. 
In addition to these demographic measures the CPS provides information on the industry in which the worker's main job is located. If defined narrowly enough, indicators of industrial attachment can be viewed as proxies for technology (for the $\mathrm{a}_{\mathrm{jt}}$ in (2)), so that they should be included if we wish to isolate the effects of crime on the equilibria of work timing. In the CPS the definitions of industries were altered between the 1978 and 1985 surveys, so that one cannot simply use the actual coding to adjust for industrial affiliation. Instead, I aggregate at various levels to construct 58 industries (some essentially two-, some three-digit SIC categories) that are consistently defined over the eighteen-year period covered by the sample. Indicator variables based on this aggregation are also included in the estimation in Section IV.

There is no obvious way to measure crime for purposes of inferring its impact on the equilibrium structure of work timing. The ideal data would show crime rates by time of day. Unfortunately, such data are simply not available, instead being reported as aggregates over long periods of time (a year). The ideal data would also show the rate of each major crime at both the worker's residence and his/her job location, or even crime rates over the worker's route of commuting. Regrettably, the CPS data do not tell us the jurisdiction in which the worker resides: We only know whether he/she lives in the central city or a suburb of an MSA. Moreover, no information is given in the CPS on the location of the worker's place of employment. While data on crime rates are available for some specific jurisdictions within MSAs, this is not true for all jurisdictions, and even the central city-suburban distinction is not always available from the earlier years that match the CPS data.

Given these difficulties with the CPS data and with the available data on crime, we are thrown back on using information on crime rates that cover the entire MSA where the worker resides. The 
data are from various issues of the FBI's uniform crime reports, available by area and state annually. ${ }^{3}$ I append these published data to the records of the individual workers in the CPS samples. For workers in MSAs that are included in the crime reports the crime rate for the MSA is included. For workers outside those MSAs I assume that their decisions are motivated by the statewide crime rate and append that datum to the file for them. These data are quite far from meeting all the desiderata indicated above. To the extent that they are error-ridden, however, they will bias all the effects that we estimate toward zero and reduce the chances of finding any relationship between crime rates and the timing of work.

In addition to all the well-known problems of reporting crimes that arise in other contexts, one would like to measure fear of crime rather than the actuality of crime, since the former is presumably relevant in determining timing. Indeed, to the extent that the fear of crime in an entire MSA is what affects workers' decisions, our inability to obtain data on crime specific to the location of a worker's residence or job may not be so great a problem. There is no satisfactory way of measuring fear of crime on a disaggregated basis over time, so that I assume faute de mieux that fear is directly proportional to the reported actuality of crime. ${ }^{4}$ This assumption is justified by the evidence (Skogan [13, p. 77]) that expressed fear of crime is highly positively correlated crosssectionally with actual crime rates.

I assume that reported crime rates, $\underline{\text { both levels and changes, }}$ are correct measures of actual criminality. The validity of this assumption presumably differs by type of crime. Thus rather than aggregating into one index, all the estimates are based on rates of criminality by type of crime. Since I wish to concentrate on fear of crime against the person, I include measures of rates of homicide, rape, robbery and aggravated assault. ${ }^{5}$ 
I have presented temporal patterns and secular trends in the $\mathrm{L}_{\mathrm{t}}$ elsewhere (Hamermesh [5] [6]), and there is no need to take up space with them here. Suffice it to note that, of those men who worked at all in 1991, over 7 percent were working at the least intensively worked time of day (3AM). Evening and night work, while not standard, is not rare. Not surprisingly, given female employees' lower average hours, the fractions of women workers who are at work are below those of men at nearly all times.

Table 1 presents descriptive statistics of the crime rates that were linked to the CPS data. Because there may be differences between the very largest MSAs and other large areas, I disaggregate the sample into the top 5 MSAs by population average over the 1973-91 period, other large (over 2.5 million population) MSAs, and the remaining workforce. Except for homicide, crime rates were rising over this period, especially the reported rate of aggravated assault. In all categories and at all times the reported crime rates are higher in the large MSAs than elsewhere; and, except for rape in 1985 and 1991, crime rates were higher in the five largest MSAs than in other areas. As the standard deviations suggest, however, there is tremendous variation in these rates across areas, so that the frequency distributions of crime rates in the top five and other large MSAs overlap substantially each other and those in other areas. This heterogeneity provides some hope that there is sufficient variation in crime rates to allow the possibility of accounting for the facts described in Section I.

\section{DOES CRIME EXPLAIN THE CITY-SIZE EFFECT?}

Before examining this question it is worth checking that the differences in work timing by size of MSA hold in all the available data, not only in 1991 as already documented. Figures 1a and 1b show the differences in the fraction of people at work at each hour of the day between workers in 
large MSAs and other workers in May 1973, 1978, 1985 and 1991. Adjusted for differences in average total hours worked per day, there is consistently significantly less work in the evenings and at nights in the larger MSAs, and significantly more work performed during the daytime hours than elsewhere. Note that in Figure 1a there is some evidence that the differences between men in large MSAs and other areas became more pronounced over time (although there is no obvious trend among female workers). This gives an additional hint that considering crime, or the fear of crime, as an explanation of inter-area differences in work timing might be useful: If the fear of crime grew in large metropolitan areas relative to the rest of the country, one might expect this pattern of changing work timing to arise, even absent any relative increase in actual crime rates.

What follows is a variety of attempts to discover whether the city-size effects on the timing of work shown in Figures 1 are real, or merely reflect correlations of city size and workers' and job characteristics; and I examine the direct impact of crime on work timing. I estimate the coefficients $\alpha, \beta$ and $\gamma$ from probit models treating $\mathrm{L}_{\mathrm{icts}}$ as an indicator that equals one if the underlying response $l_{\text {icts }}>0$, where:

$$
l_{i c t s}=\alpha_{\mathrm{t}} \mathrm{Z}_{\mathrm{is}}+\beta_{\mathrm{t}} \mathrm{TOP5}_{\mathrm{cs}}+\beta_{\mathrm{t}}^{\prime} \mathrm{LARGE}_{\mathrm{cs}}+\gamma_{\mathrm{t}} \mathrm{CRIME}_{\mathrm{cs}}+\delta_{\mathrm{t}} \mathrm{YEAR}_{\mathrm{s}}+\epsilon_{\mathrm{icts}}, \mathrm{t}=1, \ldots 24,
$$

and $\mathrm{s}=1973, \ldots, 1991 ; \mathrm{Z}$ represents the vector of worker and job characteristics discussed in Section III; TOP5 indicates residence in one of the five largest MSAs; LARGE indicates residence in another large MSA; CRIME is the vector of crime rates in MSA or nonmetropolitan area $\mathrm{c}$ where person $\mathrm{i}$ resides in year $\mathrm{s}$; YEAR is a vector of indicator variables for the years $\mathrm{s}$, and $\epsilon_{\mathrm{i} \mathrm{ct}}$ is a random disturbance in the probit describing the probability that worker i observed in year s is at work at time t. I estimate the probits separately for men and women. While the results presented here are based 
on the probits with the data pooled over the four years, separate probits for each year yield qualitatively identical conclusions. ${ }^{6}$

The initial question is whether the addition of the vectors $\mathrm{Z}$ and CRIME alters the conclusion that the pattern of work timing in large MSAs differs from that elsewhere. Figures 2 present the estimated $\beta_{\mathrm{t}}$ and $\beta_{\mathrm{t}}$, for men and women for the four pooled CPS cross-sections. The standard errors of these estimates are typically 0.003 or less, so that except for a few of the $\beta_{t}^{\prime}$ for men, and many of them for women, the estimates are significantly different from zero. It is especially noteworthy that the estimated effects on work timing of location in the very largest metropolitan areas are highly significantly nonzero. Most important, the parameter estimates show very clearly that, even accounting for each worker's demographic characteristics, each area's industrial structure and its crime rate, there is less evening and night work in large MSAs than elsewhere. ${ }^{7}$ Indeed, the levels and patterns of the $\beta_{\mathrm{t}}$ and $\beta_{\mathrm{t}}$, look quite similar to the raw differences in the averages of the $\mathrm{L}_{\mathrm{t}}$ that were presented in Figures 1. One reasonable explanation is that there is something unobservably different about workers' characteristics and preferences, and/or in technology, in large MSAs that leads to temporal equilibria there that involve less evening and night work there.

To examine how criminality in an area affects patterns of work-timing we could report the estimates of the $\gamma_{t}$ from (3). The difficulty with those estimates is that there may be some areaspecific effect, $v_{c}$, that we cannot observe but that is correlated with crime rates. This fixed effect might, for example, reflect differences in the level of policing, the propensity to report crimes, attitudes toward crime, or any characteristic that differs among areas and does not change over time within an area. To account for this fixed effect I define a vector $\mathrm{M}$ of indicator variables, one for each separate area (MSA or rest-of-state) and respecify the index function in (3) as: 


$$
l_{\text {icts }}=\alpha_{\mathrm{t}} \mathrm{Z}_{\mathrm{is}}+\gamma_{\mathrm{t}} \mathrm{CRIME}_{\mathrm{cs}}+\delta_{\mathrm{t}} \mathrm{YEAR}_{\mathrm{s}}+\delta_{\mathrm{ct}}^{\prime} \mathrm{M}_{\mathrm{ic}}+\epsilon_{\mathrm{icts}}, \mathrm{t}=1, \ldots 24
$$

The estimates of $\gamma_{t}$ from (3') are then uncontaminated by any correlation between crime rates and unobservable area-specific characteristics. In this fixed-effects model any estimated impacts of crime rates on work timing that we find are due solely to intra-area changes in crime rates. Of course, by including the $\mathrm{M}_{\mathrm{i}}$, we subsume any effect of permanent inter-area differences in crime rates in the estimates of the $\delta_{c \mathfrak{t}}$, so that the estimated $\gamma_{t}$ potentially exclude some of the impact of crime on work timing.

Each estimated $\gamma_{t}$ comes from equation (3') pooled over all four CPS samples, so that each equation contains over 100,000 observations. Despite that, and no doubt because of the inclusion of area fixed effects, only a few of the $\gamma_{t}$ for rates of reported robbery or aggravated assault are significantly different from zero at conventional levels. These effects are also very tiny, so that I do not present them here and ignore them in the subsequent discussion.

Figures $3 \mathrm{a}$ and $3 \mathrm{~b}$ show the estimates of the $\gamma_{\mathrm{t}}$ for homicide separately for men and women. The coefficients are almost all significantly nonzero, and they are not small. Moreover, and unlike most other crimes, there are relatively few problems of systematic reporting errors for homicides. Higher homicide rates are generally associated with lower propensities to work evenings and nights, exactly as is predicted by utility-maximizing consumer's behavior in the presence of firms' offers of evening/night work at wage premia. That the effects for women are larger in percentage terms (since women's propensity to work evenings and nights is less than men's) is consistent with the impact of demographic differentials in the fear of crime discussed in Section II.

Many of the $\gamma_{t}$ on the rate of criminal rape, shown in Figures 3c-d, are significant, particularly the coefficients for both sexes in the night hours. Surprisingly, higher reported rape rates (actually, 
increases in these rates within an area over time) are associated with relatively more work at night and in the evenings. This result is quite inconsistent with the arguments about the impact of workers' and firms' maximizing responses to crime or to fear of crime. One possibility is that we should ignore the results, because reporting problems may be more serious for rape than for other violent crimes. Why these reporting problems would generate this striking and counter-intuitive pattern of coefficients is, however, absolutely unclear.

Another possible explanation is that the positive effect is an artifact that would disappear if we isolated the impact of variations in the rate of criminal rape on the work behavior of the most likely predators and victims, younger persons. To examine this possibility I interacted the four crime measures with an indicator of the individual's age (less than 30). While the interactions with the other three crime measures were generally insignificant, the interaction with the rape rate was positive and significant for men in the evenings and nights, negative and significant for women then. Indeed, the main effects and interactions are such that older men's choice of work timing is unaffected by variations in the rate of criminal rape, while younger women are deterred from evening/night work when and where rape rates are higher. This suggests that the implications of the theory about the impact of the fear of crime on the behavior of different demographic groups are confirmed.

The finding that differences in the threat of homicide alter work patterns in a way consistent with the theory is uncontaminated by correlations with any unchanging area-specific characteristic. ${ }^{8}$ It may, however, be the spurious result of a correlation of changing crime rates within areas with changes in some other characteristic that is related to work timing. One possibility (devoid of any theoretical basis but still worth pursuing) is that faster population growth is associated with more rapid increases in crime, and that such growth is associated with a movement away from evening and 
night work. Comparing changes in crime rates within MSAs to changes in MSA populations from 1973 to 1991, we find no evidence supporting even the precondition for this possibility: None of the correlations of population growth with any of the four crime rates is significantly different from zero even at the 90 -percent level.

Yet another possibility is that work timing is affected by the homicide rate, but that the total homicide rate is the wrong measure to use, since it includes many murders that result from intrafamily disputes. The fraction of all murders that were committed within families declined between 1976 and the early 1990s; and it may have done so at different rates across areas. To account for this, I reestimated (3') using all workers located in those areas for which I could obtain data on the fraction of homicides accounted for by family members. ${ }^{9}$ Adding this measure in no way changed the pattern of coefficients shown in Figures $3 \mathrm{a}$ and $3 \mathrm{~b}$.

Another possibility is that including only the worker's industry in the vector Z is not sufficient, and that excluding his or her occupation may be biasing the estimated impacts of TOP5 and LARGE in (3) and of the crime rates in (3'). To account for this possibility I added a large vector of quite narrowly defined occupations to these equations. Again, no qualitative change in the main results of this section -- the continuing significance of the city-size effects, and the negative impact of the homicide rate on the propensity to work evenings/nights -- was detected.

It seems quite likely that the incidence of the most serious and most carefully reported crime -homicide -- affects the timing of work in the expected directions. Despite that, differences in work timing between workers in large metropolitan areas and those elsewhere are not significantly reduced once criminal activity and a host of demographic and industrial characteristics are accounted for. The first puzzle posed in the introduction is not explained by differential risks of crime. 
The second puzzle outlined in the Introduction is the national trend away from evening and night work over this period. To examine this issue, for each $\mathrm{t} I$ compare the variance of the coefficients $\delta_{t}$ from (3') to the variance of these same coefficients from equations in which only the three indicator variables for $\mathrm{YEAR}_{\mathrm{s}}$ are included. For both men and women the variances of these coefficients are typically higher in the equations that include all the demographic, industry and crime variables, and MSA fixed effects, than in the raw data. The secular trend toward reduced evening/night work is not accounted for by any of the factors that are included in this study. ${ }^{10}$

\section{A NEW PERSPECTIVE ON THE ECONOMIC COST OF CRIME}

There has been a variety of estimates of the direct monetary cost of crime in the United States. For example in 1994 the value of stolen property (through robberies, burglaries, larcenies and stolen motor vehicles) alone was $\$ 8$ billion. ${ }^{11}$ This entire sum may not represent an economic cost, since it is in part a transfer (involuntary, to be sure) from one owner of the property to another. Other sources of economic loss, however, such as the value of lives lost to homicide, the value of lost workdays resulting from crime victims' injuries, etc., surely add greatly to the total cost of crime in the United States. Crime also imposes indirect monetary costs on society by forcing people and firms to reallocate their activities to reduce the risk of becoming a victim of crime. Many of these are monetary expenditures (see, for example, Cook [2]) designed to reduce one's risk of becoming a victim, and such activities themselves generate externalities, both negative and positive (Ayres and Levitt [1]).

Possibly as important as these monetary costs, and apparently not heretofore measured (and perhaps not even pointed out) are the indirect nonmonetary costs of crime as it affects the use of time. Even a simple activity, like walking out of one's way to avoid a dark street where the risk of crime 
is believed to be high, engenders some time costs that would not arise in a crime-free society. As the theoretical discussion in Section II showed, absent crime we would observe some equilibrium allocation of workers by timing of work. In the presence of crime that allocation is altered, with the changes presumably reflecting a reduction in economic well-being. We can measure the cost of the shift in work timing away from the crime-free equilibrium by assuming that evening and night work pays a premium that induces workers to labor at these undesirable times. In the absence of crime more work would be performed at such times. With higher crime rates the incentive to labor then (the evening/night wage premium) becomes insufficient for some of the workers to overcome their fear of crime. Such workers thus implicitly forego some earnings, and society is shifting production away from times when the marginal worker will be more productive, because of the deterrent that crime (or fear of crime) has created.

We can measure the indirect cost of crime that results from an inefficient allocation of work timing as:

$$
\text { Loss }=-\theta *[\mathrm{WE}] \sum_{\mathrm{t}=8 \mathrm{PM}}^{6 \mathrm{AM}} \Delta \mathrm{H} \cdot \gamma_{\mathrm{Ht}},
$$

where $\Delta \mathrm{H}$ is the simulated change in the homicide rate (the one crime that we examined whose reporting is likely to be fairly free of errors, and the one whose impacts on work timing were most often significantly nonzero); $\gamma_{\mathrm{H} t}$ is the marginal impact of a one-unit increase in the homicide rate on the propensity to work at time $\mathrm{t}$, and WE is the national wage bill. The term $\theta *[\mathrm{WE}]$ thus measures the total (extra) price paid nationally for evening and night work. I assume that there is a constant wage premium $\theta^{*}$ that would prevail during the evening and night hours in a labor market from which the fear of homicide is absent. The terms $\Delta \mathrm{H} \cdot \gamma_{\mathrm{Ht}}$ use the estimates of the previous section to calculate the impact of the simulated change in the homicide rate on the propensity to work at time 
$t$, and thus measure the effect of a one-unit increase in the homicide rate on the quantity of evening/night work performed.

We obviously cannot measure $\theta *$. Clearly, however, $\theta *<\theta$, the existing premium for evening and night work: Some part of whatever premium we observe being paid for evening/night work reflects compensation for the risk of becoming a homicide victim. Regrettably, good estimates of $\theta$ are very difficult to produce. Some estimates have been generated for the United States (Kostiuk [8]; Schumacher and Hirsch [11]; Shapiro [12]) suggesting that $\theta$ is around 10 percent, but perhaps as much as 25 percent. Assuming that at most half of the observed pay premium is compensation for the risk of becoming a homicide victim, in calculating the loss in (4) I use the range $[0.05,0.125]$ to proxy what the evening/night pay premium $\theta^{*}$ would be.

The $\gamma_{\mathrm{H}}$ are taken from the fixed-effects estimates (equations (3')); E is national 1996 employment, and W is average hourly earnings in 1996. Finally, to err on the conservative side I simulate a change in the homicide rate $(\Delta \mathrm{H})$ of -9.39 per 100,000 population, the difference between the lowest average homicide rate in the four years in the sample and the highest minimum in those four years. (This amounts to a drop in the homicide rate of around 75 percent, a huge decline, but one that would still leave the U.S. homicide rate above that in most industrialized nations.) Given the sizes of the $\gamma_{\mathrm{H}}$, the simulated change in the homicide rate would lead to an increase in evening and night work of around 0.2 hours per person (and, with the assumptions that underlay the estimation of (3'), an offsetting decline in daytime work). ${ }^{12}$

Under these assumptions the welfare cost of the effect of homicide on work timing is between $\$ 4$ billion and $\$ 10$ billion (depending on the value of $\theta^{*}$ chosen). ${ }^{13}$ (This ignores the role of riskaversion in the typical worker's utility function, which means our estimates are biased upward to some 
unknown extent.) On a per-worker basis this amounts to between $\$ 32$ and $\$ 80$ per year. Under a reasonable range of discount rates the present values of these sums are roughly between $\$ 300$ and $\$ 2000$. Assuming that the risk of being a homicide victim is greater in the evening and at night, these amounts that workers are willing to forego to avoid evening and night work do not seem large compared to an hedonic value of life that has been estimated to be around \$10 million (Viscusi [14]).

As a fraction of American GDP the indirect cost of homicide that is generated through its impact on the timing of work is obviously minute; but even the lower figure of $\$ 4$ billion is half the value of stolen property in the United States, suggesting that indirect economic costs are a large but insufficiently considered by-product of a socially harmful activity. The magnitude of these effects suggests that there may be substantial and previously unconsidered economic benefits from legislation and investments that would reduce the American homicide rate. For example, if even one-third of the murders in which handguns are the proximate cause of death could be avoided by restrictions on owning handguns, the implied reduction in the indirect economic cost resulting from the altered patterns of work timing would be between $\$ 1.1$ and $\$ 2.8$ billion. $^{14}$

\section{CONCLUSIONS}

We started with two "mysteries" describing the timing of work in America: A lower propensity to work evenings and nights in large metropolitan areas, and a secular decline in evening and night work. One possible explanation for these phenomena is the existence of higher crime rates in large metropolitan areas, rates that may have been increasing secularly. To examine this possibility I have linked household data on the timing of work from 1973 to 1991 to FBI crime reports. The evidence is quite clear that neither of these mysteries is explained by changes or inter-area differences in crime rates. 
There is a variety of explanations for the difference in work timing by size of area, although none of them is readily testable. One attractive explanation is that economies of temporal agglomeration are complementary with economies of spatial agglomeration. The failure to account for secular shifts in work timing also has a variety of possible explanations, with the simplest one being supply-side responses to rising real full incomes.

I find significant impacts of inter-area differences in homicide rates on work timing: Higher homicide rates deter working in the evening and at night and shift it to the daytime. This finding is robust to changes in specification that allow for unmeasurable area-specific effects. It is consistent with the theory of the determination of equilibrium patterns of work timing and with observed wage premia for evening/night work.

Criminal activity imposes negative externalities on the labor market, because crime, or the fear of crime, generates departures from optimal patterns of work timing. The magnitude of the impacts of homicide rates on work timing suggests that this cost is between $\$ 4$ and $\$ 10$ billion. More important than this specific calculation is the general implication that social pathologies alter the timing of work and, indeed, the timing of economic activities generally, and that the sizes of these effects can be approximated. These additional negative externalities are costs that problems of homelessness, noninstitutionalized mental patients, and other difficulties impose on society. Their magnitude offers the hope of additional, previously unnoticed benefits to successful attempts at the amelioration of these social problems. 


\section{REFERENCES}

1. I. Ayres and S. Levitt, Measuring Positive Externalities from Unobservable Victim Precaution: An Empirical Analysis of Lojack, Quarterly Journal of Economics, 113, 43-78 (1998).

2. P. Cook, The Demand and Supply of Criminal Opportunities, Crime and Justice, 7, 1-27 (1986).

3. J. Dominitz and C. Manski, Perception of Economic Insecurity, Public Opinion Quarterly, 61, 261-287 (1997).

4. E. Glaeser, B. Sacerdote and J. A. Scheinkman, Crime and Social Interactions, Quarterly Journal of Economics, 111, 507-548 (1996).

5. D. Hamermesh, The Timing of Work Over Time, Economic Journal, 109 (1999), forthcoming.

6. ---------, "Workdays, Workhours and Work Schedules," The W.E. Upjohn Institute, Kalamazoo, MI (1996).

7. J. V. Henderson, The Economics of Staggered Work Hours, Journal of Urban Economics, 9, 349364 (1981).

8. P. Kostiuk, Compensating Differentials for Shift Work, Journal of Political Economy, 98, 10541075 (1990).

9. J. F. McDonald and S. Balkin, Citizen Demand for Exposure to Street Crime, Urban Studies, 20, 419-429 (1983).

10. S. Rosen, The Theory of Equalizing Differences, in "Handbook of Labor Economics" (O. Ashenfelter and R. Layard, Eds.), North-Holland, Amsterdam (1986).

11. E. Schumacher and B. Hirsch, Compensating Differentials and Unmeasured Ability in the Labor Market for Nurses: Why Do Hospitals Pay More? Industrial and Labor Relations Review, 50, 557 579 (1997).

12. M. Shapiro, Capital Utilization and the Marginal Premium for Work at Night, Unpublished paper, University of Michigan (1995).

13. W. Skogan, "Disorder and Decline," The Free Press, New York (1990).

14. W. K. Viscusi, The Value of Risks to Life and Health, Journal of Economic Literature, 31, 19121946 (1993). 
15. G. Winston, "The Timing of Economic Activities," Cambridge University Press, New York (1982). 
Table 1. Descriptive Statistics, Crime Rates by Location, 1973-91

\section{Homicide Rape Robberies Aggravated NOBS}

Top 5 MSAs:

Assault

$\begin{array}{cccccc}1973 & 14.13 & 38.01 & 454.98 & 331.75 & 5895 \\ & (2.27) & (11.44) & (188.36) & (86.01) & \\ 1978 & & & & & 5255 \\ & 14.66 & 42.25 & 467.20 & 379.11 & \\ 1985 & (2.85) & (16.17) & (237.84) & (143.88) & 7715 \\ & & & & & \\ 1991 & 12.23 & 41.36 & 528.48 & 442.41 & 10382 \\ & (4.65) & (13.82) & (270.88) & (172.97) & \\ & 13.68 & 35.86 & 570.66 & 579.10 & (312.74) \\ & (8.01) & (12.24) & (353.29) & \end{array}$

Other Large MSAs:

$\begin{array}{cccccc}1973 & 10.79 & 31.26 & 305.76 & 203.42 & 3962 \\ & (6.05) & (14.16) & (134.74) & (86.72) & \\ 1978 & & & & & 4547 \\ & 11.69 & 41.36 & 300.77 & 258.50 & \\ 1985 & (6.25) & (14.82) & (96.81) & (87.77) & 5971 \\ & & & & & \\ 1991 & 10.76 & 48.82 & 326.31 & 321.98 & 7821 \\ & (5.59) & (15.75) & (97.29) & (67.71) & \end{array}$

Other:

$\begin{array}{llllll}1973 & 9.32 & 23.76 & 162.56 & 190.06 & 35247 \\ & (4.20) & (7.83) & (95.81) & (79.29) & \\ 1978 & 8.29 & 29.99 & 156.71 & 239.06 & 41550 \\ & (4.15) & (12.95) & (100.24) & (115.83) & \\ 1985 & 6.89 & 34.86 & 156.14 & 279.03 & 48694 \\ & (3.61) & (14.86) & (117.60) & (141.66) & \\ 1991 & 7.99 & 45.55 & 195.31 & 388.58 & 42738 \\ & (5.71) & (20.35) & (165.67) & (248.42) & \end{array}$




\section{FOOTNOTES}

1. McDonald and Balkin [9] offer a somewhat related model that links people's willingness to venture out of their homes at night to their subjective probability of being victimized by crime.

2. All the analysis presented in the text is based on this question. Using it ignores the possibility that actual patterns of work timing may differ once one accounts for second jobs. Reestimates of the equations presented here using those workers (94 percent of the total) who worked on only one job showed no qualitative changes in the results.

3. These are published by the FBI under the title Uniform Crime Reports for the United States in the earlier years and as Crime in the United States, in the later years.

4. While there is no evidence that fear of crime is growing faster than crime rates, there is substantial evidence (e.g., Dominitz and Manski [3]) that the belief that one will be a victim of crime far exceeds the fraction of people who are victimized.

5. No doubt other crimes might affect the timing of work/leisure; but as a reasonable entry into this topic I concentrate on crimes against the person because they seem most likely to generate nonzero values of the $\phi_{i t}$; reporting of them is likely to be better, and, due to their greater capacity to generate fear, the causation is more likely to be unidirectional to work timing.

6. The decision to work at hour $t$ is in general not independent of the decision to work at hour $\mathrm{t}+1$. Thus $r\left(\epsilon_{\mathrm{ist}}, \epsilon_{\mathrm{ist}+1}\right) \neq 0$ in the estimates of (3) for $\mathrm{t}=1, \ldots 24$. If we were to estimate (3) using a linear-probability model, this dependence would not alter the estimated parameters, since the vectors of regressors in each equation are the same. With a (nonlinear) probit model this independence property of seemingly-unrelated least-squares estimation no longer holds, so that more efficient estimates are possible; but the computational burdens of estimating a system of 24 interrelated probits containing often 70 independent variables on over 100,000 observations are prohibitive. That the results obtained here did not differ qualitatively when (3) was estimated using a linear-probability model suggests that accounting for the intercorrelation of the error terms would have only minor effects on the estimated probit parameters.

7. The inclusion of the large vector of industry indicators should account for any technologyinduced changes in the spatial agglomeration of finance/home offices that might have occurred over this sample period.

8. I thank Vernon Henderson for suggesting this potential problem.

9. The unpublished table demonstrating this fact was provided by Daniel Nagin. The data used in the calculations were provided by Phyllis Reuther.

10. While a variety of theoretical arguments (e.g., Henderson [7]) suggest the potential impact of commuting costs (especially time costs) on the time-series pattern of changing work timing, attempts to explain the trend using Census information on commuting times showed no impact on the pattern of work timing.

11. Calculated from Statistical Abstract of the United States, 1996, Table 318. 
12. Because the length of the workday is implicitly held fixed in (3'), summing in (4) from 8PM through 6AM and weighting earnings by the evening/night premium correctly account for the extra costs generated by the induced shift in work timing.

13. Even this estimate may be viewed as a lower bound, insofar as it does not account for the responses to crime through changes in the location of work, and thus in work timing, that we cannot take into account here.

14. Calculated based on the simulations reported above and data for 1994 on the type of weapon used in murders, from Statistical Abstract, 1996 Table 314. 